\title{
AULA INVERTIDA: ROMPIENDO LOS PARADIGMAS TRADICIONALES
}

MSc. Rosa Amelia Moreira Ortega

Docente titular tiempo completo

Instituto Superior de Formación Profesional

rosa.moreira@formacion.edu.ec

Palabras claves: Ccase invertida, TIC's, proceso de enseñanza -aprendizaje.

Keywords: flipped clasroom , ICT, Teaching -learning process.
Recibido: 12 de agosto de 2016

Aceptado: 19 de octubre de 2016

\section{RESUMEN}

Las TIC's han propiciado profundos cambios en nuestra sociedad, en particular en la última década, ha impactado en diversos ámbitos, como el económico, político, cultural o social. Hablar de aula invertida es hablar de innovación y autonomía, significa un cambio en los salones de aulas, cambiar los métodos tradicionales de enseñanza enviando instrucciones en línea fuera del salón de clase a través de soportes tecnológicos, de forma que el docente pueda destinar ese tiempo a otras actividades de participación y colaboración durante la clase. En ese sentido, el presente artículo reflexiona sobre el aula invertida como una forma de romper paradigmas tradicionales en el proceso de enseñanza -aprendizaje y potenciar un aprendizaje diferente, autónomo y desarrollador en docentes y estudiantes.

\section{ABSTRACT}

ICT has led to profound changes in our society. Particularly in the last decade, as in any other before, it has impacted various areas, including the economic, political, cultural or social one. Talking about flipped classroom is talking about innovation and autonomy. It is a change in the classrooms, it is to invert the traditional teaching methods by sending online instructions outside the classroom through technological media used outside the classroom so that the teacher can spend that time on other participation and collaboration activities during class.

The key point is to understand that is not properly in ICT, but the activities carried out both students and faculty thanks to the possibilities of communication, exchange, access and processing of information offered to them. Paradigms are broken not because of the profesor's will, but because learning is conditioned by the society in which we are born and evolve as noted by Vygostky. Taken this as main ground, the present article reflects of the flipped classroom as a way to break with the traditional teaching paradigms 


\section{INTRODUCCIÓN}

Las Tecnologías de la Información y la Comunicación (TICs) han propiciado profundos cambios en nuestra sociedad, particularmente en la última década, donde se ha producido un impacto en diversos ámbitos como el económico, político, cultural o social. Sin embargo, las amplias posibilidades de la tecnología no pueden darse en todos los contextos de la misma forma, ya que no todas las personas tienen acceso a los avances tecnológicos de forma equitativa.

El pedagogo Marc Prensky considera que el sistema educativo necesita un nuevo currículo y de nuevos métodos y procedimientos de enseñanza aprendizaje, más a tono con los cambios que se está produciendo con la nueva tecnología de la informática y la comunicación.

La mayoría de los productos para la educación a la venta se convierten en meras ayudas para enseñar la malla existente, basados en la falsa idea de que se necesita enseñar lo que sabemos de forma academicista y frontal.

La educación tradicional a la que estamos acostumbrados se torna predominantemente conductista, ya que en muchas ocasiones el docente desempeña el papel más activo, explicando y trasmitiendo sus saberes enciclopédicamente. Mientras que el alumno adopta una actitud más pasiva de simple receptor de una amplia gama de conocimientos.

Sin embargo, hablar de aula invertida o flipped classroom es hablar de innovación, autonomía y flexibilidad. Se requiere hacer un cambio de mentalidad de todos los que intervienen en el proceso de enseñanza aprendizaje, fundamentalmente los docentes, quienes tienen que estar actualizados tecnológica, pedagógica y didácticamente para afrontar nuevos salones de aulas, laboratorios y métodos más productivos, siendo competentes para diseñar y aplicar instrucciones en línea a través de soportes tecnológicos para ser utilizados fuera del salón de clases.

Se asume a Raad (2015) que una de las ventajas fundamentales que tiene el aula invertida es que, utilizada adecuadamente por el docente, puede estimular la participación y colaboración de los alumnos durante la clase. Algunos de los servicios en línea que más puede motivar esa visión colaborativa del aprendizaje son las plataformas como YouTube entre otras. .

A partir de todo lo planteado el interés se centra en cómo utilizar una estrategia metodológica innovadora, que incluya el aula invertida, como motivadora de la comunicación, el intercambio, el acceso y procesamiento de la información de forma productiva e independiente.

El objetivo principal es fundamentar la importancia del aula invertida para estimular el aprendizaje productivo y autónomo de los estudiantes con vistas al mejoramiento de su aprovechamiento académico, a través de la aplicación de estrategias metodológicas que viabilicen el uso de las TICS.

\section{DESARROLLO}

El flipped classroom es un término acuñado por Jonathan Bergmann y AaronSams (2012), dos profesores de química en Woodland Park High School en Woodland Park Colorado, que significa literalmente "aula invertida". 
El flipped classroom es un término acuñado por Jonathan Bergmann y AaronSams (2012), dos profesores de química en Woodland Park High School en Woodland Park Colorado, que significa literalmente "aula invertida".

Ambos idearon una solución para evitar que los alumnos perdieran clases, para ello grababan los contenidos a impartir y los distribuían entre sus alumnos para que los visualizaran en su casa antes de la clase, mientras que el trabajo en el aula consistía en diseñar y realizar proyectos para poner en práctica los conocimientos adquiridos y resolver dudas. Se comprobó que de esta manera las calificaciones de los alumnos fueron mejorado progresivamente.

La implementación de este modelo se ha visto favorecida por las potencialidades que la Web 2.0 que ofrece nuevas posibilidades para la búsqueda, creación, publicación y sistematización de los conocimientos, información y recursos a través de INTERNET, ofreciendo nuevas perspectivas para desarrollar el proceso de enseñanza-aprendizaje y minimizar los roles tradicionales que asumen algunos docentes y estudiantes hoy dia.

Se trata de un modelo nuevo de dar clases, donde se prioriza un enfoque integral para incrementar el compromiso, la participación activa y creadora del estudiante en su aprendizaje debido a las ventajas que ofrece.

\section{Ventajas del enfoque aula invertida}

- Permite combinar la clase con otros tipos de actividades más individualizadas, productivas y creativas con los alumnos

- $\quad$ Permite una distribución no lineal de las mesas en el aula, lo cual potencia el ambiente el intercambio y la colaboración.

- $\quad$ Fomenta la motivación, la innovación, productividad y racionalidad con el uso de las nuevas tecnologías.

\section{- $\quad$ Los contenidos están accesibles al aprendiz en cualquier momento}

- $\quad$ Involucra a las familias u otros agentes promotores del aprendizaje.

Estas ventajas se hacen evidentes ya que se puede asimilar el contenido teniendo en cuenta el ritmo, las estrategias y estilos de aprendizaje que distinguen a cada estudiante, al tiempo que le posibilita que tenga el control de lo que aprende.

A través de este enfoque se fomenta el trabajo cooperativo, la interacción social y la resolución de problemas en forma grupal, esto va a llevar optimizar el tiempo de clases y a minimizar los deberes mecanizados. El papel de los docentes es más bien de guía, de conductor de los estudiantes para que puedan aprender las lecciones en casa, a su ritmo, comunicándose con sus compañeros y profesores vía on-line.

El modelo dirigido por el docente implica Just-in-Time Teaching (JiTT), en español, método justo a tiempo. En la mayoría de los entornos de aprendizaje JiTT, los estudiantes responden a las asignaciones electrónicas dadas poco antes de la clase. Después del plazo especificado, el docente revisa las presentaciones de los estudiantes "justo a tiempo", y utiliza estos datos para ajustar la clase, de forma que esta se adapte mejor a las necesidades de los estudiantes y poder aclarar aquellos temas que puedan ser confusos para el grupo. 
Estos ambientes flexibles permiten al estudiante poder elegir cuándo y dónde aprenden, lo que ofrece mayor flexibilidad a sus expectativas como aprendices. Los profesores permiten y aceptan el desconcierto que puede generarse durante la clase, estimulando nuevas maneras de hacer. Se establecen evaluaciones apropiadas que permiten valorar el entendimiento de una manera significativa para los estudiantes y profesores.

La importancia aula invertida está en que motiva a desarrollar una cultura de aprendizaje, en la producción de un cambio deliberado en la aproximación al aprendizaje de una clase centrada en el profesor a una en el estudiante, el tiempo en el aula permite profundizar más en los temas, crear oportunidades más enriquecedoras de aprendizaje y maximizar las interacciones cara a cara para asegurar el entendimiento y síntesis del material.

Las TIC's de hoy están redefiniendo las aulas del futuro a través de la educación en línea, lo cual conllevará a una transformación de las maneras de hacer y aprender. Se requiere que los estudiantes cuenten con acceso a computadoras y dispositivos móviles conectados a INTERNET, de manera que se abran más estas oportunidades educativas de interacción entre los profesores y estudiantes.

Entre estas formas de interacción están, por ejemplo, los foros, chats, museos virtuales, laboratorios virtuales, etc, las cuales propician nuevas experiencias acerca del aprendizaje invertido y permitirán ampliar el acceso a una educación superior de calidad. Este nuevo modelo comienza a ser muy popular debido a la forma de reorganizar la instrucción y de manejar más eficiente y enriquecedora el tiempo de clase.
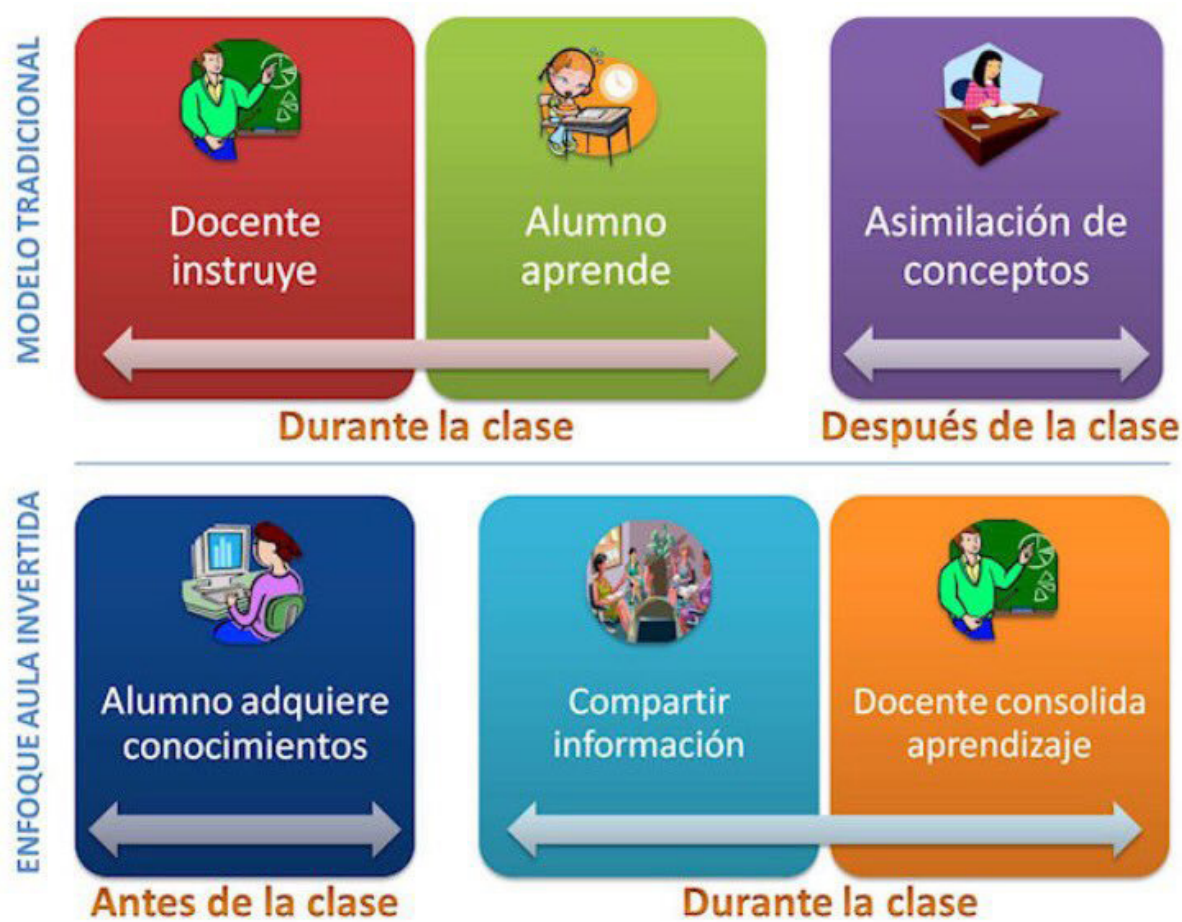

Fuente: http://www.nubemia.com/aula-invertida-otra-forma-de-aprender/ 
Se connota que, estas novedosas formas de aprender implican un cambio de paradigma, con novedosos conceptos sustentados en un marco teórico que fundamenta un proceso de enseñanza aprendizaje interactivo, colaborativo y autónomo en las universidades del actual siglo XXI, donde la sociedad del conocimiento impone nuevos retos y desafíos a docentes y estudiantes como entes activos, innovadores y transformadores capaces de desarrollar, a decir de Vygotsky, sus potencialidades, las del grupo y de su entorno socio cultural.

\section{CONCLUSIONES}

El aula invertida o flipped classroom promueve la asunción de un nuevo rol tanto de los docentes como los alumnos para enseñar y aprender constructiva y colaborativamente los conocimientos, potenciando la responsabilidad, la colaboración y la autonomía de todos durante el proceso de aprendizaje.

Aunque este modelo pedagógico de no puede aplicarse en el $100 \%$ de los casos, ya que requiere de recursos, condiciones y conocimientos tecnológicos a veces no accesibles, si se constituye en un gran reto para la universidad del actual siglo XXI, donde la era del conocimiento y las nuevas tecnologías son cada vez mayores y el efecto de este modelo se hace más indispensable.

Se trata de un nuevo paradigma basado en la implicación, la participación, construcción y colaboración del alumno a través de una enseñanza más individualizada y personalizada, que demanda del docente mayores niveles de actualización, autoaprendizaje y capacitación para poder materializarlo en la práctica pedagógica.

Esta novedosa forma de asumir el proceso de enseñanza aprendizaje va a adquiriendo cada vez mayor importancia por forma constructiva, colaborativa, autónoma y desarrolladora de aprender, para que docentes y alumnos puedan estar a tono con su tiempo y no quedarse a la zaga del desarrollo. 


\section{REFERENCIAS BIBLIOGRÁFICAS}

Coll, C. (2004). "Psicología de la Educación y prácticas educativas mediadas por las tecnologías de la información y la comunicación: Una mirada constructivista", en Sinéctica, núm. 25, México, Instituto Tecnológico y de Estudios Superiores de Occidente

Raad, A. (2015). Invirtiendo la clase, Chile, Educarchile

http:www.nubemia.com

http:www.teduca3.wikispaces.com

http://www.eluniverso.com/vida-estilo

http://es.slideshare.net/siriuselearning/el-aula-invertida

http://www.youtube.com/watch?v=ePOnnOH9GMY

https://www.youtube.com/watch?v=s4k9mPLKPIc

https://es.wikipedia.org/wiki/Aula_invertida

http://www.oei.es/divulgacioncientifica/?Aula-invertida-para-un-aprendizaje

https://carlosluisgomezvalderrama.wordpress.com/2014/07/04/ensenar-es-transformar-y-romper-los-paradigmas-soy-un-desobediente/ 